\title{
Is being overweight associated with engagement in self-injurious behaviours in adolescence, or do psychological factors have more "weight"?
}

\author{
Marta Freitas-Rosa ${ }^{1}$ (i) $\cdot$ Sónia Gonçalves ${ }^{1} \cdot$ Henedina Antunes $^{2,3,4}$
}

Received: 17 July 2015/ Accepted: 22 December 2015

(C) Springer International Publishing Switzerland 2016

\begin{abstract}
Introduction The purpose of this study was to examine the prevalence of non-suicidal self-injurious behaviours (NSSI) among healthy weight and overweight adolescents and to examine the role of age, gender, weight status, treatment condition for weight control, and psychological variables (psychopathological symptoms and emotional skills) in the prediction of NSSI.

Methods The study had a cross-sectional design, and participants $(n=370)$ were aged $14-19$ years and were divided in three groups: 205 adolescents with normal weight, 82 adolescents from the community with overweight/obesity, and 83 adolescents with overweight/obesity and in outpatient treatment for weight control.

Results The prevalence of these behaviours in the overweight community group (25.6\%) and in the overweight clinical group (14.5\%) was similar to their healthy weight peers $(19 \%)$. Not attending an outpatient treatment for weight control, higher psychopathology and less ability to regulate emotions predict the presence of NSSI.

Conclusion Being overweight is not associated with NSSI, but psychosocial variables such as psychopathology,
\end{abstract}

Marta Freitas-Rosa

martafreitasrosa@gmail.com

1 School of Psychology, University of Minho, Campus Gualtar, 4710 Braga, Portugal

2 Pediatric, Gastroenterology, Hepatology and Nutrition Unit of Bragás Hospital, Braga, Portugal

3 Life and Health Sciences Research Institute (ICVS), School of Health Sciences, University of Minho, Braga, Portugal

4 ICVS/3B's-PT Government Associate Laboratory, Guimarães, Braga, Portugal emotional deregulation and the absence of medical care predict these behaviours.

Keywords Self-injurious - Overweight - Adolescence · Psychopathology $\cdot$ Emotion

\section{Introduction}

Non-suicidal self-injurious behaviour (NSSI), defined as socially non-acceptable behaviour involving a direct and deliberate injury to the body without suicidal intent [1], is a growing and dangerous phenomenon among adolescents.

Data on the prevalence of NSSI seems to vary depending on the setting of NSSI and the methods used in their assessment. However, NSSI rates appear to be high in adolescents and young adults, both in community and clinical samples. It has been verified that NSSI begins in adolescence [1], with 13-23\% of adolescents reporting these behaviours at some time in their lives [2].

There is some evidence of the association between eating disorders such as anorexia nervosa and bulimia nervosa and NSSI [3-5]. According to a literature review, the occurrence of NSSI ranged between 13.6 and $42.1 \%$ for people with anorexia nervosa restrictive type, between 27.8 and $68.1 \%$ for people with anorexia nervosa compulsive type/laxative intake, and between 26 and $55.2 \%$ for people with bulimia nervosa [6].

However, little is known about the prevalence and the relationship between NSSI and overweight/obesity in adolescence. Only a few recent studies [7-11] have attempted to understand the relationship between weight and these behaviours in adolescence. For instance, Claes and colleagues [7] showed that NSSI is less common in patients with extreme low and extreme high body weights. Previous 
studies [12, 13] had shown that body mass index (BMI) can be positively correlated with the presence of behavioural problems, including aggression and self-injury, as a way of dealing with body dissatisfaction. There is also evidence that perceived body image (too thin or too fat) can be related to engagement in self-harm behaviours [14]. Thus, the association between being overweight and NSSI may operate through multiple psychological mechanisms, such as body image and emotional regulation strategies. Tresno, Ito, and Mearns [15] found that frequency of NSSI was associated with low expectations of regulation of negative mood. There is also evidence that the presence of NSSI may reflect some type of psychopathology [14, 16, 17].

According to Nock [1], NSSI may represent different behavioural forms of affective and social regulation. Regarding the model of experiential avoidance (experiential avoidance model-EAM) [18], NSSI is used as a form of escape and/or to reduce negative emotional responses. Through a vicious cycle, these behaviours lead to temporary relief or function as an avoidance strategy of emotions, memories or intolerable and aversive thoughts, which probably reinforces and strengthens the NSSI [18]. Accordingly, Claes, Klonsky, Muehlenkamp, Kuppens, and Vandereycken [19] also found in a sample of patients with food and intake disorders that the reason "to prevent or suppress negative feelings" was the most reported for engaging in NSSI, while social reasons such as "draw the attention of others", were less indicated.

Current models of NSSI and eating disorders [18, 20, 21] have proposed that both are body-focused disorders and are related to self-regulation deficits and body dissatisfaction. More recently, Muehlenkamp [22] proposed that body regard may moderate the association between emotion dysregulation and NSSI. Although these conceptual models are not specific to obesity, both obesity and eating disorders share some psychological mechanisms (e.g., emotional dysregulation and body dissatisfaction) and specific eating behaviours (e.g., binge eating). Therefore, the present study is the first, as far as we know, to compare NSSI of overweight adolescent students with their healthy weight peers by considering both community and clinical samples. Thus, the aims of the present research were to assess differences in these behaviours between groups according to weight and to examine the role of specific variables such as age, gender, weight, treatment condition, psychopathology and emotional skills on the presence of NSSI. The hypotheses of the present study are: (1) overweight adolescents report more NSSI than their normal weight peers; and (2) the variables with stronger capacity to identify the presence of NSSI are overweight, psychopathology and emotional difficulties.

It is imperative to continue the scientific work to clarify the complex relationship between emotion regulation, weight and NSSI.

\section{Methods}

\section{Participants}

A total of 370 participants aged 14-19 years of both genders in the 9-12th grades at elementary schools were recruited in the north of Portugal. The participants were separated into the following three groups: (a) a Community Group with normal weight comprising 205 adolescents with healthy weight (percentiles values between P5 and P85), who were randomly recruited in three public schools and who were not receiving psychotherapy or following a medical/nutritional programme for weight control; (b) a Community Group with overweight/obesity comprising 82 adolescents with overweight/obesity (percentile values $\geq$ P85) who were not receiving psychotherapy or any type of medical or nutritional treatment for weight control, randomly recruited in three public schools; and (c) a Clinical Group with overweight/obesity comprising 83 adolescents with overweight/obesity (percentile values $\geq$ P85) who were not receiving psychotherapy but were following a medical or nutritional treatment at the Gastroenterology, Hepatology and Paediatric Nutrition outpatient unit of Braga's Hospital in Portugal.

\section{Measures}

\section{Weight}

The $\mathrm{kg} / \mathrm{m}^{2}$ ratio was used to calculate BMI adjusted by sex and age. Adolescents with normal weight were defined as having a BMI lower than the 85th percentile. Overweight and obese adolescents were defined as having a BMI in the 85-94th percentiles and in the 95th percentile or higher, respectively, according to the centers for disease control and prevention growth charts for US children [23].

\section{Socio-demographic questionnaire}

Basic demographic information was collected from all participants (e.g., age, school year, gender and parent's occupation). Socioeconomic level was measured with data on parents' education level (i.e., elementary school, secondary school, trade school or university).

\section{Self-injury questionnaire - treatment related (SIQ-TR) [24]}

The self-injury questionnaire is a self-report consisting of six groups. Five of these groups ask for data concerning information about five dissimilar self-injurious behaviours (scratching, hurting, cutting, burning and biting oneself). The last group consists of a set of questions that also 
evaluate characteristics of a self-injurious behaviour, but in this last group, the participant freely reports the self-injurious behaviour in which he/she engages that has not been previously described. For each group, self-injurious behaviour characteristics are evaluated, including whether the behaviour has ever been practiced, how many times, and the frequency of the behaviour, the body parts affected, the intensity and frequency of the pain, related emotions (previous and post-behaviour), and reasons for engaging in self-injurious behaviour. The original version of this questionnaire had very favourable psychometric characteristics.

\section{Brief symptom inventory (BSI) [25]}

The BSI is an abbreviated form of the Symptom Checklist-90 (SCL-90) used to identify self-reported, clinically relevant psychological symptoms as well as their intensity (from 0 to 4 ) at a specific time point. The BSI consists of 53 Likert-type items that cover nine symptom dimensions (somatization, obsession-compulsion, interpersonal sensitivity, depression, anxiety, hostility, phobic anxiety, paranoid ideation and psychoticism) and three global indices of distress (global severity index (GSI), positive symptom distress index, and positive symptom total). These global indices measure current or past symptomatology levels, the intensity of symptoms, and the number of reported symptoms, respectively. The global severity index (GSI, the mean of the 53 symptoms) was used in all analyses, where higher scores indicate more psychopathological symptoms. The psychometric characteristics of the Portuguese version attest to its satisfactory internal consistency, which justifies its use in identifying psychological disturbances. The BSI has been shown to be a reliable and valid measurement of Portuguese adolescents. Our sample obtained a high level of internal consistency $(\alpha=.96)$.

\section{Emotional skills and competence questionnaire (ESQC) [26]}

This self-report measure was originally developed in Croatia by Taksic (2000) and has been used in different contexts (academic and professional). The ESQC is classified as a "trait emotional intelligence" or "perceived emotional intelligence" measure. The ESQC contains 45 Likert-type items that are scored on a scale of 1 (never) to 6 (always)" with higher scores reflecting superior emotional skills. It has three subscales: (i) the ability to perceive and understand emotion (15 items); (ii) the ability to express and label emotion (14 items); and (iii) the ability to manage and regulate emotion (16 items). The Cronbach's alpha coefficient in the current sample was 92 .

\section{Procedure}

This study was approved by the Ethics in Research Committee of Braga's Hospital in Portugal and followed the ethical procedures outlined in the declaration of Helsinki. An initial request explaining the research goals and data collection procedures was sent to the medical and academic institutions. Parents and adolescents provided written informed consent and were assured that their data would remain anonymous and confidential.

At schools, the weights and heights of participants were objectively measured by the investigator after the participants completed the questionnaires. To avoid constraints related to weight, each participant's weight was measured in private, standing without shoes, looking forward and positioned in the centre of the balance. Participants' heights were measured with feet together and knees against a wall. At the hospital, the anthropometric evaluation was performed by nurses prior to the individual administration of the questionnaires.

Exclusion criteria precluded individuals who had neurological problems and BMIs below the 5th percentile in the normal weight group to avoid biasing the sample with possible cases of eating disorders, such as anorexia nervosa. The cross-sectional study design compared the three groups, two by two: the normal weight group vs. the overweight community group, the normal weight group vs. the overweight clinical group, and the overweight community group vs. the overweight clinical group. In the present study, we dichotomized the self-injury behaviours, following guidelines similar to those outlined by the 2007 National Youth Risk Behaviour Survey (YRBS) Data User's Manual [27]. Dichotomous variables represent the percentage of adolescents who report that they do or do not participate in a NSSI.

\section{Results}

\section{Participants' characteristics}

We conducted all the analyses using SPSS statistical software (version 19.0 for Windows, SPSS Inc.). Standard descriptive analyses of the entire study sample and their socio-demographic features were performed in the first step.

As shown in Table 1, the mean ages of the control group, the overweight community group and the overweight clinical group were 16.20 years $(\mathrm{SD}=1.19)$, 16.29 years $(\mathrm{SD}=1.57)$ and 15.55 years $(\mathrm{SD}=1.30)$, respectively. We found significant between-group differences in mean age $(p<.001)$. Post hoc analyses revealed that the overweight clinical group of adolescents was 
Table 1 Socio-demographic features by group

\begin{tabular}{|c|c|c|c|c|c|}
\hline Variables & $\begin{array}{l}\text { Normal weight } \\
n=205 \\
M(\mathrm{SD})\end{array}$ & \multicolumn{2}{|c|}{$\begin{array}{l}\text { Overweight community } \\
n=82 \\
M(\mathrm{SD})\end{array}$} & $\begin{array}{l}\text { Overweight clinical } \\
n=83 \\
M(\mathrm{SD})\end{array}$ & $\begin{array}{l}\text { Test } \\
F\end{array}$ \\
\hline Age & $16.20(1.19)$ & & & $15.55(1.30)$ & $8.58 * * *$ \\
\hline \multirow[t]{2}{*}{ BMI } & $20.79(1.94)$ & & & $30.63(3.95)$ & $419.34 * * *$ \\
\hline & \multicolumn{2}{|c|}{$n(\%)$} & $n(\%)$ & $n(\%)$ & $\chi^{2}$ \\
\hline \multicolumn{6}{|l|}{ Sex } \\
\hline Male & \multicolumn{2}{|c|}{$74(36.1)$} & $40(48.8)$ & $35(42.2)$ & \multirow[t]{2}{*}{.130} \\
\hline Female & \multicolumn{2}{|c|}{$131(63.9)$} & $42(51.2)$ & $48(57.8)$ & \\
\hline \multicolumn{6}{|c|}{ Socioeconomic status } \\
\hline Low & \multicolumn{2}{|c|}{$3(1.5)$} & $3(3.7)$ & $2(2.4)$ & \multirow[t]{5}{*}{.323} \\
\hline Low-middle & \multicolumn{2}{|c|}{$125(61)$} & $58(70.7)$ & $60(72.3)$ & \\
\hline Middle & \multicolumn{2}{|c|}{$64(31.2)$} & $19(23.2)$ & $19(22.9)$ & \\
\hline Middle-high & \multicolumn{2}{|c|}{$11(5.4)$} & $1(1.2)$ & $2(2.4)$ & \\
\hline High & \multicolumn{2}{|c|}{$2(1)$} & $1(1.2)$ & $0(0)$ & \\
\hline
\end{tabular}

younger than both the overweight community group $(p<.01)$ and the normal weight group $(p<.001)$. The community groups did not differ with regard to age ( $p=.914)$.

The mean BMIs of the clinical, overweight community and control groups were $30.63 \mathrm{~kg} / \mathrm{m}^{2} \quad(\mathrm{SD}=3.95)$, $29.49 \mathrm{~kg} / \mathrm{m}^{2}$ (SD = 4.19), and $20.79 \mathrm{~kg} / \mathrm{m}^{2}(\mathrm{SD}=1.94)$, respectively. As expected, we found significant differences in the mean BMI among the three groups $(p<.001)$. Post hoc analyses revealed significant differences between the overweight groups and the normal weight group $(p<.001)$. We also found marginally significant differences between the clinical and the overweight community groups $(p=.06)$. It is common for obese/overweight individuals in the general population to have BMIs that are slightly lower than clinical groups. This study did not find significant between-group differences with regard to sex ( $p=.13$ ) or socioeconomic level $(p=.32)$. The majority of the participants in the three groups (normal weight adolescents, overweight adolescents from the community and overweight adolescents in treatment) were from a lower-middle socioeconomic level $(61,70.7$ and $72.3 \%$, respectively), and more than half of the participants in each group were female $(63.9,51.2$ and $57.8 \%$, respectively).

\section{Group comparison regarding prevalence of NSSI}

The frequencies of adolescents who ever engaged in selfinjurious behaviour in the normal weight group, the overweight community group and the overweight clinical group were 19, 25.6 and $14.5 \%$, respectively. The most frequently reported form of self-injury in the three groups of adolescents was self-cutting, with $9.3 \%$ of the normal weight group, $12.2 \%$ of the overweight community group and $8.4 \%$ of the overweight clinical group performing this behaviour. NSSI were compared across the three groups using a binary logistic regression analysis. Overweight adolescents from the community were similar to their normal healthy weight peers in the prevalence of all behaviours related to self-injurious behaviours (see Table 2). The clinical overweight group was similar to the normal weight group in the prevalence of all self-injurious behaviours. Compared with the overweight community group, we found in the overweight clinical group lower odds and frequencies with regard to current or past selfinjurious $(14.5$ vs. $25.6 \%$, respectively; $p<.10$; $\mathrm{OR}=2.04)$, although this finding was only marginally significant.

\section{The role of weight, treatment condition and psychosocial factors in the presence of NSSI}

Regarding the variables that may identify the presence of NSSI, the data were analysed using hierarchical logistic regression. Self-injurious behaviours were treated as outcome variables, while age, gender, weight, treatment condition (receiving or not receiving treatment) and psychological dimensions were integrated into the regression model. For each analysis, the outcome variable was dichotomized into the presence or absence of self-injurious behaviour. Gender, weight, and treatment condition were entered as dichotomous variables. $p$ values below .05 were considered statistically significant.

Thus, we applied a regression analysis with blocked entry procedures. For each logistic regression, age and gender were entered in an initial step, followed by the cumulative impact of weight and treatment condition, and psychological variables were introduced in the final step. 
Table 2 Prevalence and odds ratios for self-injurious behaviours among community groups with normal weight and overweight and clinical group with overweight

\begin{tabular}{|c|c|c|c|c|c|c|c|c|c|}
\hline \multirow[t]{2}{*}{ Variables } & \multirow{2}{*}{$\begin{array}{l}\text { Normal } \\
\text { weight group } \\
n=205 \\
n(\%)\end{array}$} & \multirow{2}{*}{$\begin{array}{l}\text { Overweight } \\
\text { community } \\
\text { group } n=82 \\
n(\%)\end{array}$} & \multirow{2}{*}{$\begin{array}{l}\text { Overweight } \\
\text { clinical group } \\
n=83 \\
n(\%)\end{array}$} & \multicolumn{2}{|c|}{$\begin{array}{l}\text { Normal weight vs. } \\
\text { overweight } \\
\text { community group }\end{array}$} & \multicolumn{2}{|c|}{$\begin{array}{l}\text { Normal weight vs. } \\
\text { overweight clinical } \\
\text { group }\end{array}$} & \multicolumn{2}{|c|}{$\begin{array}{l}\text { Overweight community } \\
\text { vs. overweight clinical } \\
\text { group }\end{array}$} \\
\hline & & & & $p$ & OR $(95 \% \mathrm{CI})$ & $p$ & OR $(95 \% \mathrm{CI})$ & $p$ & OR $(95 \% \mathrm{CI})$ \\
\hline \multicolumn{10}{|c|}{ Self-injurious behaviours } \\
\hline $\begin{array}{c}\text { Current or } \\
\text { past self- } \\
\text { injurious }\end{array}$ & $39(19.0)$ & $21(25.6)$ & $12(14.5)$ & .21 & $.68(.37-1.25)$ & .36 & $1.39(.69-2.81)$ & $.07^{+}$ & $2.04(.93-4.48)$ \\
\hline $\begin{array}{l}\text { Ever } \\
\text { scratched } \\
\text { one's self }\end{array}$ & $12(5.9)$ & $6(7.3)$ & $6(7.2)$ & .65 & $.79(.29-2.17)$ & .66 & $.80(.29-2.20)$ & .98 & $1.01(.31-3.28)$ \\
\hline $\begin{array}{l}\text { Ever hurt } \\
\text { one's self }\end{array}$ & $18(8.8)$ & $8(9.8)$ & $2(2.4)$ & .80 & $.89(.37-2.14)$ & $.07^{+}$ & $3.90(.88-17.19)$ & $.07^{+}$ & $4.38(.90-21.28)$ \\
\hline $\begin{array}{l}\text { Ever cut } \\
\text { one's self }\end{array}$ & $19(9.3)$ & $10(12.2)$ & $7(8.4)$ & .46 & $.74(.33-1.66)$ & .82 & $1.11(.45-2.75)$ & .43 & $1.51(.55-4.17)$ \\
\hline $\begin{array}{l}\text { Ever } \\
\text { burned } \\
\text { one's self }\end{array}$ & $9(4.4)$ & $4(4.9)$ & $1(1.2)$ & .86 & $.89(.27-2.99)$ & .21 & $3.77(.47-30.2)$ & .20 & $4.21(.46-38.45)$ \\
\hline $\begin{array}{l}\text { Ever bited } \\
\text { one's self }\end{array}$ & $19(9.3)$ & $7(8.5)$ & $5(6.0)$ & .85 & $1.09(.44-2.71)$ & .37 & $1.59(.58-4.42)$ & .54 & $1.46(.44-4.79)$ \\
\hline $\begin{array}{l}\text { Ever tried } \\
\text { another } \\
\text { self- } \\
\text { injury }\end{array}$ & $0(0)$ & $1(1.2)$ & $0(0)$ & 1.00 & $.00(.00)$ & .00 & $4.05(.00)$ & 1.00 & $.00(.00)$ \\
\hline
\end{tabular}

Table 3 Predictors of selfinjurious behaviours

\begin{tabular}{|c|c|c|c|c|c|}
\hline Self-injurious behaviours & Model & $\beta$ & Wald & OR & $p$ \\
\hline \multicolumn{6}{|l|}{ Block 1} \\
\hline Age & & .17 & 2.13 & 1.18 & .15 \\
\hline Gender $^{\mathrm{a}}$ & $\chi^{2}(2)=7.11 *$ & -.37 & 1.39 & .69 & .24 \\
\hline \multicolumn{6}{|l|}{ Block 2} \\
\hline Weight status ${ }^{\mathrm{b}}$ & & -.36 & 1.09 & .69 & .29 \\
\hline Treatment condition $^{\mathrm{c}}$ & $\chi^{2}(4)=10.20^{*}$ & .95 & 4.15 & 2.58 & $.04 *$ \\
\hline \multicolumn{6}{|l|}{ Block 3: psychological dimensions } \\
\hline Psychopathology (total score) & & 1.23 & 20.07 & 3.41 & $.00 * * *$ \\
\hline Perceiving emotion & & .18 & .33 & 1.20 & .56 \\
\hline Expressing/labelling emotion & & -.05 & .03 & .95 & .87 \\
\hline \multirow[t]{2}{*}{ Managing/regulating emotion } & & -1.01 & 8.14 & .36 & $.004 * *$ \\
\hline & $\chi^{2}(8)=60.04 * * *$ & & & & \\
\hline
\end{tabular}

a Gender: 0-female; 1-male

b Weight status: 0-normal BMI; 1-overweight

c Treatment condition: 0 -without treatment; 1-in treatment for weight control

$* p<.05$

$* * p<.01$

$* * * p<.001$

Table 3 lists the $\chi^{2}$ changes for the different steps of the model as well as the Wald's value and relative risk ratio for the cumulative impact composite for each of the outcomes.
We obtained a significant model $\left(\chi^{2}(8)=60.04\right.$, $p<.001)$ that correctly identified $80.4-81.5 \%$ of the subjects across the outcomes. In the first block, we found 
that gender regression coefficients were not significant. Similarly, in the second block we also found that the weight regression coefficients were not significant. However, the condition of being in treatment to lose weight was associated with the absence of NSSI. The inclusion of psychological dimensions showed that engagement in NSSI was associated with higher levels of psychopathology and by a lower ability to manage and regulate emotions.

\section{Discussion}

This study aimed to compare the prevalence of NSSI in normal and overweight/obese adolescents and to evaluate psychosocial variables that may be associated with these behaviours. These are the first published data, as far as we know, characterizing these behaviours of adolescents according to their weight (overweight or non-overweight) and treatment condition for weight loss (receiving or not receiving treatment).

The prevalence rates of NSSI of $14.5-25.6 \%$ for lifetime current or past self-injurious behaviours found in this study were similar to those found by a recent study, where $17 \%$ of a sample of students reported that they had harmed themselves deliberately in the past 12 months [14]. Another study identified a higher rate, with $56.4 \%$ of a sample of young adolescent girls $(n=53)$ engaging in self-injurious behaviour at least once in their lifetimes [27]. Unlike eating disorder populations, which tend to have a higher prevalence of self-injurious behaviours [28], overweight populations tend to report a lower prevalence of these behaviours. Self-cutting was the most common method of deliberate self-harm behaviour in this study, in line with previous studies [29-32].

When comparing the three groups, our major findings were that the clinical group of overweight adolescents had fewer NSSI than either the overweight community group or the normal weight controls. These results are consistent with many studies with clinical samples that found no such association between the presence or absence of NSSI and a variety of eating disorders and morbid obesity [33, 34]. In addition, we obtained similar ratios of NSSI in the overweight community group and the normal weight group. In fact, the literature shows that it is the adolescents with low BMI who are at higher risk of engaging in NSSI [35].

The lower risk of engaging in NSSI reported by the overweight clinical group in our study may be explained by the fact that health care professionals are well positioned to care for overweight children and to provide preventive counselling [36, 37]. Another possible explanation may be social desirability because this evaluation was performed in a medical context. Although confidentiality of the participants' data was ensured, and the participants answered the questionnaires without their parents present, there is evidence in the literature that adolescents in certain types of medical care may worry about disclosure of sensitive health information to their parents [38]. Despite these possibilities, in general the results suggest that excess weight neither protects against nor increases the risk of engaging in self-injury.

Regarding variables with strong capacity to identify the presence of NSSI, we found that gender was not associated with current or past self-injurious behaviour, which is similar to several studies that found no gender differences regarding NSSI [16, 39]. However, these results contrast with some studies reporting more NSSI among females than males [40, 41]. On the other hand, not attending an outpatient treatment for weight control was significantly associated with the occurrence of NSSI. These results support, once more, the role of health professionals in reducing such behaviours and in influencing the knowledge, attitudes and behaviours of adolescents by providing them with accurate information [42].

In addition, weight was not related to NSSI. It is possible that weight concern and perceived body image (too fat) may be correlated with these risk behaviours more than weight by itself [14], but not all overweight adolescents who are dissatisfied with their body image engage in NSSI [8]. Therefore, the understanding of NSSI does not involve just a single variable, but a combination of different psychosocial factors [20, 22, 35, 39]. It is possible that difficulties in emotion regulation and psychopathology have a more prominent role in the understanding of NSSI than the condition of being overweight and/or body dissatisfaction.

In fact, a higher level of psychopathology and a lower ability to manage and regulate emotions were, in our study, associated with engagement in NSSI. These findings are similar to those obtained by other investigators, who found in a community sample of young adolescent girls an association between internal distress (depressive symptoms) and engaging in NSSI for emotional regulation [28]. Other data showed that having unhealthy weight control behaviours, high levels of depression symptoms, poor selfesteem or poor problem-solving coping strategies were important concomitants of repeat-incidents of deliberate self-harm [14, 42]. Previous studies with clinical samples also found an association between self-injurious behaviours and a larger number of psychopathological dimensions [15, 16]. A recent review of the literature [43] suggests an affect-regulation model supported by the following empirical evidence: first, most individuals who engage in self-injurious behaviour assume that this is a method to reduce negative affect; second, studies suggest that negative affect precedes self-injury; and finally, self-injury 
causes reductions in negative affect. This model describes self-injury as a maladaptive affect-regulation strategy.

Thus, it is plausible that some psychological dimensions have a stronger association with the engagement in NSSI than weight per se. Our results support this assumption because the regression model became stronger with the inclusion of psychological dimensions. Although it is not possible to infer the direction of the relationship from the results of this study, it is reasonable to consider that higher psychopathology and emotional dysregulation can be related to the presence of NSSI among both normal and overweight adolescents.

This study has several important strengths, such as the inclusion of treatment condition (receiving or not receiving treatment for weight control), as an explanatory factor for some differences in the prevalence of NSSI among overweight adolescents. This is the first published study, as far as we know, to evaluate risk behaviours among adolescents by considering not only weight but also clinical and nonclinical populations.

This study has also limitations. Only self-reports were used for measuring psychosocial variables, and the study had a cross-sectional design. We were unable to establish a causal direction, which suggests the need to conduct studies with a longitudinal design. This study also did not evaluate the frequency and severity of NSSI, only the current and lifetime history regarding the presence/absence of this behaviour.

In conclusion, the findings of the present study support the hypothesis that the frequency of NSSI in overweight adolescents is similar to the frequency observed in their normal-weight peers. Thus, overweight adolescents are not necessarily at increased risk of NSSI. Other variables related to outpatient treatment for weight control, psychopathology and emotional regulation are more closely linked to self-injurious behaviours than is weight. The results highlight the importance of considering these variables and the different patterns of self-injury when preventing such behaviours in youth populations.

\section{Compliance with ethical standards}

Conflict of interest The authors report no conflicts of interest. The authors alone are responsible for the content and writing of the paper. This manuscript has only been submitted to this journal and has not been published, in press, or submitted elsewhere.

Ethical approval All procedures performed in studies involving human participants were in accordance with the ethical standards of the Ethics in Research Committee of Braga's Hospital and with the 1964 Helsinki declaration and its later amendments or comparable ethical standards.

Informed consent Informed consent was obtained from all individual participants included in the study.

\section{References}

1. Nock MK (2009) Why do people hurt themselves? New insights into the nature and function of self-injury. Curr Dir Psychol Sci 18:78-83. doi:10.1111/j.1467-8721.2009.01613

2. Jacobson CM, Gould M (2007) The epidemiology and phenomenology of non-suicidal self-injurious behavior among adolescents: a critical review of the literature. Arch Suicide Res 11:129-147. doi:10.1080/13811110701247602

3. Klomek A, Lev-Wiesel R, Shellac E, Hadas A, Berger U, Fenning $S$ et al (2015) The relationship between self-injurious behavior and self disclosure in adolescents with eating disorders. Eat Weight Disord 20(1):43-48. doi:10.1007/s40519-014-0145-0

4. Fischer S, Dl Grange (2007) Comorbidity and high-risk behaviors in treatment-seeking adolescents with bulimia nervosa. Int J Eat Disord 40:751-753. doi:10.1002/eat.20442

5. Haug NA, Heinberg LJ, Guarda AS (2001) Cigarette smoking and its relationship to other substance use among eating disordered inpatients. Eat Weight Disord 6(3):130-139. doi:10.1007/ bf03339762

6. Svirko E, Hawton K (2007) Self-injurious behavior and eating disorders: the extent and nature of the association. Suicide Life Threat Behav 37:409-421. doi:10.1521/suli.2007.37.4.409

7. Claes L, Fernández-Aranda F, Jimenez-Murcia S, Botell C, Casanueva F, Torre R et al (2013) Co-occurrence of non-suicidal self-injury and impulsivity in extreme weight conditions. Personal Individ Differ 54:137-140. doi:10.1016/j.paid.2012.07.035

8. Peltzer K, Penqpid S (2011) Overweight and obesity and associated factors among school-aged adolescents in Ghana and Uganda. Int J Environ Res Public Health 8(10):3859-3870. doi:10.3390/ijerp8103859

9. Croezen S, Visscher TL, Bogt NC, Veling ML, Haveman-Nies A (2009) Skipping breakfast, alcohol consumption and physical inactivity as risk factors for overweight and obesity in adolescents: results of the E-MOVO project. Eur J Clin Nutr 63:405-412. doi:10.1038/sj.ejcn.1602950

10. Arif A, Rohrer JE (2005) Patterns of alcohol drinking and its association with obesity: data from the third national health and nutrition examination survey 1988-1994. BMC Public Health 5:126. doi:10.1186/1471-2458-5-126

11. Strauss RS (2000) Childhood obesity and self-esteem. Pediatrics 115(1):105-115. doi:10.1542/peds.105.1.e15

12. Allison DB, Packer-Munter W, Pietrobelli A, Alfonso VC, Faith MS (1998) Obesity and Developmental Disabilities: pathogenesis and treatment. J Dev Phys Disabil 10:215-255. doi:10.1023/a: 1022888323684

13. Sansone RA, Sansone LA, Fine MA (1995) The relationship of obesity to borderline personality symptomatology, self-harm behaviors, and sexual abuse in female subjects in a primary-care medical setting. J Personal Disord 9(3):254-265. doi:10.1521/ pedi.1995.9.3.254

14. Wan Y-H, Hu C-L, Hao J-H, Sun Y, Tao F-B (2011) Deliberate selfharm behaviors in Chinese adolescents and young adults. Eur Child Adolesc Psychiatry 20:517-525. doi:10.1007/s00787-011-0213-1

15. Tresno F, Ito Y, Mearns J (2012) Risk factors for nonsuicidal self-injury in Japanese college students: the moderating role of mood regulation expectancies. Int J Psychol 48:1009-1017. doi:10.1080/00207594.2012.73

16. Haw C, Hawton K, Houston K, Townsend E (2001) Psychiatric and personality disorders in deliberate self-harm patients. Br J Psychiatry 178:48-54. doi:10.1192/bjp.178.1.48

17. Stanley B, Gameroff M, Michalsen V, Mann J (2001) Are suicide attempters who self-mutilate a unique population? Am J Psychiatry 158:427-432. doi:10.1176/appi.ajp.158.3.427 
18. Chapman AL, Gratz KL, Brown MZ (2006) Solving the puzzle of deliberate self-harm: the experiential avoidance model. Behav Res Ther 44:371-394. doi:10.1016/j.brat.2005.03.005

19. Claes L, Klonsky ED, Muehlenkamp J, Kuppensa P, Vandereycken W (2010) The affect-regulation function of nonsuicidal selfinjury in eating-disordered patients: which affect states are regulated? Compr Psychiatry 51:386-392. doi:10.1016/j.comppsych. 2009.09.001

20. Gratz KL (2007) Targeting emotion dysregulation in the treatment of self-injury. J Clin Psychol 63:1091-1103. doi:10.1002/ jclp.20417

21. Nock MK (2010) Self-injury. Annu Rev Clin Psychol 6:339-363. doi:10.1146/annurev.clinpsy.121208.131258

22. Muehlenkamp JJ, Bagge CL, Tull MT, Gratz KL (2012) Body regard as a moderator of the relation between emotion dysregulation and nonsuicidal self-injury. Suicide Life Threat Behav 43(5):469-588. doi:10.1111/sltb.12032

23. Kuczmarski RJ, Ogden CL, Grummer-Strawn LM, Flegal KM, Guo SS, Wei R et al (2000) CDC growth charts: United States. Advance data from vital and health statistics (publication no. 314). Hyattsville, MD: national center for health. Adv Data. doi:10.1542/peds.109.1.45

24. Claes L, Vandereyken W (2007) Self-injurious: differential diagnosis and functional differentiation. Compr Psychiatry 48:137-144. doi:10.1016/j.comppsych.2006.10.009

25. Canavarro C (1999) Inventário de Sintomas PsicopatológicosB.S.I. In: Simões M, Gonçalves M, Almeida L (eds). Testes e Provas Psicológicas em Portugal, vol 2. APPORT/SHO, Braga. doi: 10.1590/s1413-85571999000200006

26. Lima-Santos N, Faria L (2005) Inteligência emocional: Adaptação do "Emotional Skills and Competence Questionnaire" (ESCQ) ao contexto português. Revista da Faculdade de Ciências Humanas e Sociais da UFP 2:275-289

27. Centers for Disease Control and Prevention (2007). National Youth Risk Behavior Survey (YRBS) Data Users Manual. doi: 10.1037/e527542012-001

28. Hilt LM, Cha CB, Nolen-Hoeksema S (2008) Nonsuicidal selfinjury in young adolescent girls: moderators of the distressfunction relationship. J Consult Clin Psychol 76:63-71. doi:10. 1037/0022-006x.76.1.63

29. Paul T, Schroeter K, Dahme B, Nutzinger DO (2002) Self-injurious behavior in women with eating disorders. Am J Psychiatr 159(3):408-411. doi:10.1176/appi.ajp.159.3.408

30. Morey C, Corcoran P, Arensman E, Perry IJ (2008) The prevalence of self-reported deliberate self harm in Irish adolescents. BMC Public Health 8(79):1-7. doi:10.1186/1471-2458-8-79
31. Muehlenkamp JJ, Gutierrez PM (2004) An investigation of the differences between self injurious behavior and suicide attempts in a sample of adolescents. Suicide Life Threat Behav 34(1):12-23. doi:10.1521/suli.34.1.12.27769

32. Ross S, Heath N (2003) Two models of adolescent self-mutilation. Suicide Life Threat Behav 33:277-287. doi:10.1521/suli.33. 3.277.23218

33. Ross S, Heath N (2002) A study of the frequency of self-mutilation in a community sample of adolescents. J Youth Adolesc 31(1):67-77. doi:10.1023/a:1014089117419

34. Solano R, Fernández-Aranda F, Aitken A, López C, Vallejo J (2005) Self-injurious behaviour in people with eating disorders. Eur Eat Disord Rev 13:3-10. doi:10.1002/erv.618

35. Bruner R, Parzer P, Haffner P, Steen R, Roos J, Resch F et al (2007) Prevalence and psychological correlates of occasional and repetitive deliberate self-harm in adolescents. Arch Pediatr Adolesc Med 161(7):641-649. doi:10.1001/archpedi.161.7.641

36. Derbas J, Vetter M, Volger S, Khan Z, Panigrahi E, Wadden TA et al (2002) Improving weight management in primary care practice: a possible role for auxiliary health professionals collaborating with primary care physicians. Obes Weight Manag 5(5):210-215. doi:10.1089/obe.2009.0505

37. Ford CA (1997) Influence of physician confidentiality assurances on adolescents' willingness to disclose information and seek future health care. JAMA 278:1029-1034. doi:10.1001/jama.278. 12.1029

38. Ford CA, Millstein SG, Halpern-Felsher BL, Irwin CE (1996) Confidentiality and adolescents' disclosure of sensitive information. J Adolesc Health 18(2):111. doi:10.1016/1054-139x(96)00011-0

39. Briere J, Gil E (1998) Clinical correlates of self-mutilation in a sample of general psychiatric patients. Am J Orthopsychiatry 68:609-620. doi:10.1037/h0080369

40. Zlotnick C, Mattia JI, Zimmerman M (1999) Clinical correlates of self-mutilation in a sample of general psychiatric patients. J Nerv Ment Dis 187:296-301. doi:10.1097/00005053-199905000-00005

41. Andrews T, Martin G, Hasking P, Page A (2014) Predictors of onset for non-suicidal self-injury within a school-based sample of adolescents. Prev Sci 15(6):850-859. doi:10.1007/s11121-0130412-8

42. Klein JD, Wilson KM (2002) Delivering quality care: adolescents' discussion of health risks with their providers. J Adolesc Health 30:190-195. doi:10.1016/s1054-139x(01)00342-1

43. Klonsky ED (2007) The functions of deliberate self-harm: a review of the evidence. Clin Psychol Rev 27:226-239. doi:10. 1016/j.cpr.2006.08.002 